\title{
STABILITY OF ZOLEDRONATE GEL EMULSION IN VIRGIN COCONUT OIL
}

\author{
PRIMA ABIGAIL GAYATRI ${ }^{1}$, KRISNAWATI $^{1}$, MUHAMAD SAHLAN ${ }^{2,3}$, DIAH KARTIKA PRATAMI ${ }^{4}$, RETNO WIDAYATI ${ }^{1 *}$
}

${ }^{1}$ Department of Orthodontic, Faculty of Dentistry, Universitas Indonesia, Jakarta, Indonesia. ${ }^{2}$ Department of Chemical Engineering, Faculty of Engineering, Universitas Indonesia, West Java, Indonesia. ${ }^{3}$ Research Center of Biomedical Engineering, Faculty of Engineering, Universitas Indonesia, West Java, Indonesia. ${ }^{4}$ Faculty of Pharmacy, Universitas Indonesia, West Java, Indonesia.

Email: widayati22@yahoo.com

Received 30 September 2018, Revised and Accepted 27 February 2019

ABSTRACT

Objective: This study aimed to analyze the physical stability and drug content of zoledronate (ZOL) gel emulsion in virgin coconut oil (VCO) as a new pharmaceutical product at $25^{\circ} \mathrm{C}$ as room temperature and $40^{\circ} \mathrm{C}$ as an accelerated temperature for a stability physics test.

Methods: The ZOL gel emulsion comprises the following ingredients: $0.16 \%$ ZOL powder, $2 \%$ carboxymethyl cellulose, 5\% VCO, 0.44\% sodium benzoate, and $0.009 \%$ antioxidant butylated hydroxytoluene, and distilled water. Samples of this gel emulsion were stored for 1 month at $25^{\circ} \mathrm{C}$ and $40^{\circ} \mathrm{C}$, and the parameters used for stability tests were $\mathrm{pH}$, viscosity, spreadability, and adhesive strength. The drug content was also evaluated with a spectrophotometer. The ZOL gel emulsion was evaluated against these metrics on days 1, 7, 14, and 28

Results: The results showed that ZOL pH, viscosity, spreadability, adhesive strength, and drug content gel emulsion were clinically stable over 28 days of storage at $25^{\circ} \mathrm{C}$, whereas it was not stable when stored at $40^{\circ} \mathrm{C}$ for the same duration. pH value of ZOL gel emulsion significantly decreased at 28 days $(\mathrm{p}<0.05)$. Also for viscosity, adhesive strength, and drug content of ZOL gel emulsion showed statistically significant $(\mathrm{p}<0.05)$, except for spreadability value ( $p>0.05$ ). The spreadability value between ZOL gel emulsion that stored at $25^{\circ} \mathrm{C}$ and at $40^{\circ} \mathrm{C}$ showed no significant result at 7 and 14 days ( $p>0.05$ ).

Conclusion: ZOL gel emulsion was stable at $25^{\circ} \mathrm{C}$ when stored for 28 days, suggesting that this is a suitable storage temperature at which its physical stability and drug content can be maintained.

Keywords: Zoledronate, Drug stability, Virgin coconut oil, Orthodontic tooth movement.

(C) 2019 The Authors. Published by Innovare Academic Sciences Pvt Ltd. This is an open access article under the CC BY license (http://creativecommons. org/licenses/by/4. 0/) DOI: http://dx.doi.org/10.22159/ijap.2019.v11s1.18204

\section{INTRODUCTION}

Loss of anchorage and a consequent relapse during and after orthodontic treatment is one of the leading causes of a poor outcome of orthodontic treatment. Nonetheless, this problem remains a challenge for orthodontists, who are expected to create a system that can achieve desired tooth movement and which can also prevent their migration back to their original positions [1]. Anchorage methods that are commonly used include headgear, transpalatal bar, nance holding appliance, and lingual holding arch; all these are dependent on patient compliance [1-3], which, if insufficient, can increase treatment time and even result in effects such as caries and gingivitis [1,4]. Temporary anchorage devices, such as mini implants, are currently popular because they are small, easy to place and remove, and provide substantial anchorage. Although mini implants have been effective in providing maximum anchorage, several studies have shown that they are not always stable after orthodontic force delivery. Inflammation around the mini screw area and uncomfortable pain after the required procedure has also been noted $[1,5,6]$.

The application of bisphosphonate (BP) has a potential to reduce anchorage loss and relapse, in addition to other medications, such as nonsteroidal anti-inflammatory drugs and osteoprotegerin protein. $\mathrm{BP}$ has been used to treat various bone diseases associated with bone resorption such as osteoporosis, Paget's disease, multiple myeloma, and metastatic bone cancer because it can selectively inhibit osteoclast activities $[7,8]$. However, the side chain structure of the carbon atom of BP (phosphorus-carbon-phosphorus) is the key to its potency because it has a high affinity toward hydroxyapatite $[9,10]$. Recent studies show that BPs containing nitrogen (BP-N) are more potent than those without nitrogen [1]. Zoledronate (ZOL) is the newest class of BP-N that has a heterocyclic ring and is considered 10.000 times more potent than BP non-nitrogen; in addition, it has the highest bone affinity $[1,9,10]$.

Recent studies of BP injections in orthodontics have shown that it has a significant capability to inhibit osteoclast activity and reduce bone resorption [1,10-12]. However, BP injections are invasive and more painful than topical applications $[10,13]$. Studies of the topical form of ZOL gel emulsion with virgin coconut oil (VCO) by Parlina et al. have shown that osteoclast apoptosis significantly increases after $24 \mathrm{~h}$ of use in the experimental group that applied of ZOL gel emulsion and VCO [13]. The study showed that ZOL gel emulsion with VCO has a potency to be an alternative for pharmacology option for orthodontic anchorage and stability orthodontic treatment. The use of VCO as the oil component in a gel emulsion has many advantages instead of using the gel alone. Gel emulsion containing a drug has a long time to attach to the skin or mucosa, is easy to apply, has good spreadability, and is more comfortable for use by patients $[13,14]$.

Stability testing of pharmaceutical products is a complex procedure performed to evaluate the quality, safety, and effectiveness of drug formulations, and such tests add time as well as the considerable cost to the development and approval of a new drug [15]. The stability of ZOL gel emulsion as a new pharmaceutical product was never study before, so the aim of this study is to analyze and evaluate the physical stability and drug content of ZOL gel emulsion, containing VCO and preservative agent (sodium benzoate and the antioxidant butylated hydroxytoluene [BHT]) after it has been stored at room temperature $\left(25^{\circ} \mathrm{C}\right)$ and distribution temperature $\left(40^{\circ} \mathrm{C}\right)$. The parameters used for the evaluation of the ZOL gel emulsion were $\mathrm{pH}$ value, viscosity, spreadability, adhesive strength, and drug content. 


\section{MATERIALS AND METHODS}

\section{Materials}

ZOL powder was procured from Sigma-Aldrich industries (Singapore) in April 2018. VCO was purchased from Indogen Ltd. (Jakarta, Indonesia). Carboxymethyl cellulose (CMC), sodium benzoate, and the antioxidant BHT were procured from Harum Kimia CV (Jakarta, Indonesia) also in April 2018. The experiment was conducted at the Research Center for Biomedical Engineering (RCBE) and Laboratory of Pharmaceutical Formulation and Development Universitas Indonesia, Depok, West Java.

\section{Preparation of ZOL gel emulsion}

The ZOL gel emulsion was prepared by mixing all the ingredients into the oil base. $0.16 \%$ ZOL powder was dissolved in $0.17 \%$ phosphate buffer saline, and mixed with 5\% VCO, 2\% CMC, 2.05\% Tween, and 89.3\% distilled water in a beaker glass until the solution was homogenous. The $0.44 \%$ sodium benzoate and $0.009 \%$ BHT were then added to the oil and water mixture. The resulting gel emulsion was mixed with ZOL solvent using a mixer with $40 \mu \mathrm{g}$ ZOL for every $25 \mathrm{mg}$ gel.

\section{Physical and drug content stability studies}

All the gel emulsions of ZOL prepared with VCO were packed in Eppendorf tubes and checked for stability for 28 days at $25^{\circ} \mathrm{C}$ and $40^{\circ} \mathrm{C}$. Gel emulsion samples were evaluated after the formulation was prepared (baseline), at days 7,14 , and 28 , for $\mathrm{pH}$ value, viscosity, spreadability, adhesive strength, and drug content.

\section{Evaluation of ZOL gel emulsion preparations} Organoleptic evaluation

The prepared ZOL gel emulsion was visually assessed for appearance, color, consistency, taste, and odor every week until 4 weeks when stored at $25^{\circ} \mathrm{C}$ and $40^{\circ} \mathrm{C}$.

\section{pH determination test}

$1 \mathrm{~g}$ ZOL gel emulsion was dispersed in $100 \mathrm{ml}$ distilled water. The $\mathrm{pH}$ of the gel emulsion was determined using a digital $\mathrm{pH}$ meter (Eutech Instruments, USA) by completely plunging the electrode's glass into the gel emulsion.

\section{Viscosity test}

The viscosity of the ZOL gel emulsion was measured using a viscometer (Brookfield, USA) with spindle no. 6 and spindle speed $20 \mathrm{rpm}$. The corresponding dial reading was recorded at each speed.

\section{Spreadability test}

Spreadability was determined by placing the gel emulsion between two glass plates and then placing a 100 -g stone on top of the plates for $1 \mathrm{~min}$. Then, the farther diameter of the spread gel emulsion was measured.

\section{Adhesive strength test}

Adhesive strength was evaluated by putting the gel between two glass plates and placing a 250-g stone on top of the glass plates for $5 \mathrm{~min}$. Then, an 80-g glass plate was glued to one of the two plates touching the gel, and the time required for the glass plates to detach was recorded.

\section{Determination of drug content}

Drug content of the gel emulsion was determined by dissolving $100 \mathrm{mg}$ gel emulsion in $5 \mathrm{ml}$ distilled water. Next, $1 \mathrm{ml}$ of this solution was diluted with distilled water to make the volume of $5 \mathrm{ml}$. Then, the gel emulsion was subjected to analysis using spectrophotometer (Spectroquant Pharo 300, Germany). The amount of drug content was calculated from the calibration data; the absorbance was measured at $210 \mathrm{~nm}$.

\section{Statistical analysis}

Intra- and inter-observer reliabilities were analyzed using independent t-test. Data were analyzed using SPSS 23.0 version with independent t-test to assess the differences in stability of ZOL gel emulsion at $25^{\circ} \mathrm{C}$ and $40^{\circ} \mathrm{C}$ and with repeated measures analysis of variance (ANOVA) to calculate the differences in stability of ZOL gel emulsion at days 1, 7, 14, and 28 and post hoc Bonferroni test to see multiple comparisons and which parameters were different. The result was considered statistically significant when $\mathrm{p}<0.05$.

\section{RESULTS}

The result of the intra- and inter-observer reliability test with independent t-test showed that there was no significant difference for viscosity and spreadability value of ZOL gel emulsion between researches $(\mathrm{p}<0.05)$. All the stability machines had already calibrated before use. After preparation of the ZOL gel emulsion, it was evaluated for physical appearance and stability. When stored for 28 days at $25^{\circ} \mathrm{C}$, the formulation had a white viscous, creamy, smooth homogenous texture, a characteristic odor and taste of coconut extract, and no trapped bubbles. However, when stored at $40^{\circ} \mathrm{C}$ for the same duration, its consistency was found to be hard. Indeed, all the stability tests for the ZOL gel emulsion stored at $40^{\circ} \mathrm{C}$ over the 28 -day study period could not be performed due to the poor consistency of the gel emulsion. The results are summarized in Table 1.

The pH of ZOL gel emulsion at baseline was reasonably constant at about 5.79 , and it slightly decreased throughout the 28-day storage period. Table 2 showed the result of post hoc Bonferroni test of repeated measure ANOVA. The differences in mean $\mathrm{pH}$ value for ZOL gel emulsion stored at $25^{\circ} \mathrm{C}$ and $40^{\circ} \mathrm{C}$ are significantly different $(\mathrm{p}<0.05)$ (Fig. 1). The specific value of the differences for all parameters is shown in Table 2. Fig. 2 demonstrates the result of the viscosity of ZOL gel emulsion over 28 days. The viscosity ranged from 77,000 to $86,000 \mathrm{cps}$. The viscosity of the gel emulsion increased on days 7 and 14 at both temperatures and decreased on day 14 at $25^{\circ} \mathrm{C}$ storage, then raised up on day 28 (Fig. 2).

The spreadability of the emulsion at both storage temperatures decreased significantly over the 28 -day test period $(\mathrm{p}<0.05)$. These results have a nonlinear relationship to the viscosity values of the ZOL gel emulsion (Fig. 3). The values of adhesive strength of ZOL gel emulsion are summarized in Figs. 4 and 5. The increment value of adhesive strength at $25^{\circ} \mathrm{C}$ and $40^{\circ} \mathrm{C}$ during the 28 days has a linear relationship to the spreadability of the ZOL gel emulsion.

The drug content of the ZOL gel emulsion ranged from 57.62 to $55.32 \mathrm{ppm}$. The drug content value of ZOL gel emulsion was

Table 1: Organoleptic evaluation of ZOL gel emulsion

\begin{tabular}{|c|c|c|c|c|c|c|c|c|}
\hline \multirow[t]{2}{*}{ Test } & \multicolumn{8}{|l|}{ Evaluation } \\
\hline & Baseline & & Day 7 & & Day 14 & & Day 28 & \\
\hline Organoleptic & $25^{\circ} \mathrm{C}$ & $40^{\circ} \mathrm{C}$ & $25^{\circ} \mathrm{C}$ & $40^{\circ} \mathrm{C}$ & $25^{\circ} \mathrm{C}$ & $40^{\circ} \mathrm{C}$ & $25^{\circ} \mathrm{C}$ & $40^{\circ} \mathrm{C}$ \\
\hline Color & Solid white & Solid white & Solid white & Solid white & Solid white & Solid white & Solid white & Solid white \\
\hline Odor & Coconut & Coconut & Coconut & Coconut & Coconut & Coconut & Coconut & Coconut \\
\hline Taste & Coconut & Coconut & Coconut & Coconut & Coconut & Coconut & Coconut & Coconut \\
\hline Consistency & Viscous & Viscous & Viscous & Viscous & Viscous & Viscous & Viscous & Solid hard \\
\hline
\end{tabular}


Table 2: Parameters values of stability and drug content ZOL gel emulsion testing between $0,7,14$, and 28 days in $25^{\circ} \mathrm{C}$ and $40^{\circ} \mathrm{C}$

\begin{tabular}{|c|c|c|c|c|c|c|c|c|c|c|}
\hline \multirow[t]{2}{*}{ Time (days) } & \multicolumn{2}{|l|}{ pH } & \multicolumn{2}{|c|}{ Viscosity } & \multicolumn{2}{|c|}{ Spreadability } & \multicolumn{2}{|c|}{ Adhesive strength } & \multicolumn{2}{|c|}{ Drug content } \\
\hline & $25^{\circ} \mathrm{C}$ & $40^{\circ} \mathrm{C}$ & $25^{\circ} \mathrm{C}$ & $40^{\circ} \mathrm{C}$ & $25^{\circ} \mathrm{C}$ & $40^{\circ} \mathrm{C}$ & $25^{\circ} \mathrm{C}$ & $40^{\circ} \mathrm{C}$ & $25^{\circ} \mathrm{C}$ & $40^{\circ} \mathrm{C}$ \\
\hline $0-7$ & $0.021 *$ & 0.055 & 0.478 & 0.105 & 1.000 & 1.000 & 0.550 & 1.000 & $0.000 *$ & $0.000^{*}$ \\
\hline $0-14$ & $0.029 *$ & $0.001^{*}$ & 0.468 & $0.018^{*}$ & 1.000 & 0.545 & $0.003^{*}$ & $0.001 *$ & $0.000 *$ & $0.000 *$ \\
\hline $0-28$ & $0.000^{*}$ & & $0.031^{*}$ & & 1.000 & - & $0.001^{*}$ & - & $0.000^{*}$ & - \\
\hline $7-14$ & 1.000 & $0.000^{*}$ & 1.000 & 0.718 & 1.000 & 0.757 & $0.012 *$ & $0.004 *$ & $0.000 *$ & $0.000^{*}$ \\
\hline $7-28$ & $0.004 *$ & - & 0.212 & - & 1.000 & - & $0.003 *$ & - & $0.000^{*}$ & - \\
\hline $14-28$ & 0.05 & - & 1.000 & - & 1.000 & - & 1.000 & - & $0.000 *$ & - \\
\hline
\end{tabular}

Post hoc Bonferroni test. ${ }^{*} \mathrm{p}<0.05$, ZOL: Zoledronate

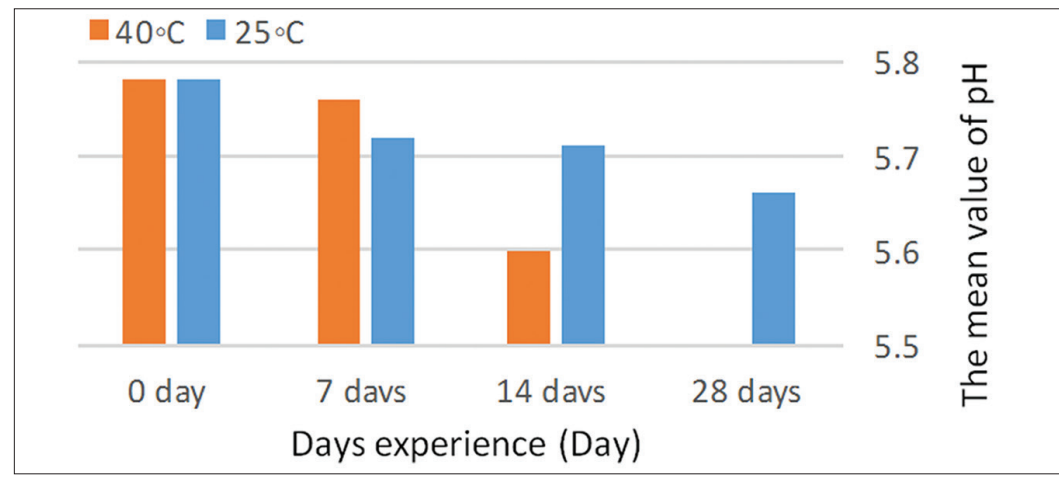

Fig. 1: Mean value of $\mathrm{pH}$ of zoledronate (ZOL) gel emulsion at $25^{\circ} \mathrm{C}$ and $40^{\circ} \mathrm{C}$. The $\mathrm{pH}$ value of both gel emulsions decreased significantly after 7 and 14 days compared to the $1^{\text {st }}$ day of testing $(\mathrm{p}<0.05)$. $\mathrm{pH}$ tests for the $\mathrm{ZOL}$ gel emulsion stored at $40^{\circ} \mathrm{C}$ over the 28 -day study period could not be performed due to the poor consistency of the gel emulsion

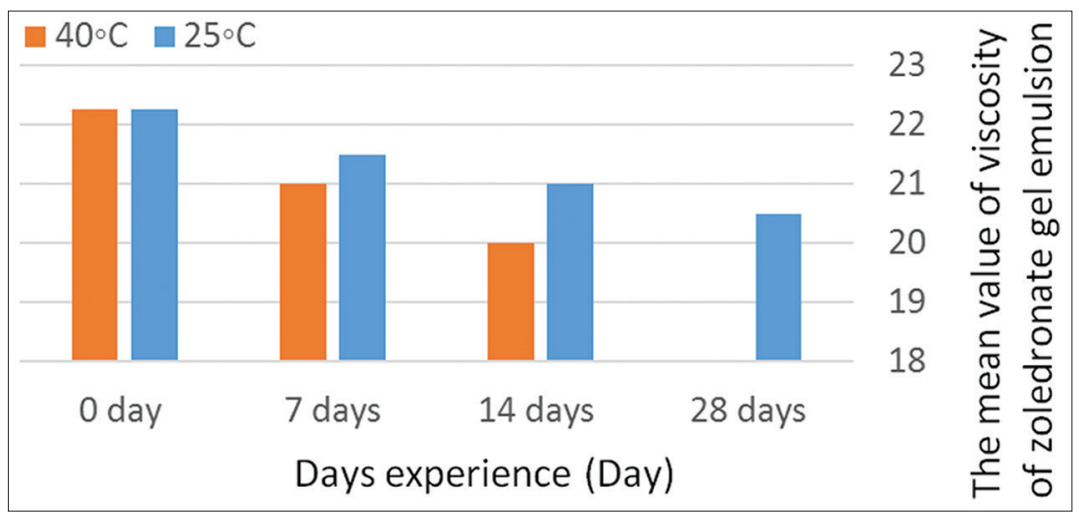

Fig. 2: Mean value of viscosity of zoledronate (ZOL) gel emulsion at $25^{\circ} \mathrm{C}$ and $40^{\circ} \mathrm{C}$ during the $28-\mathrm{d}$ study period. Viscosity tests for the ZOL gel emulsion stored at $40^{\circ} \mathrm{C}$ over the 28 -day study period could not be performed due to the poor consistency of the gel emulsion

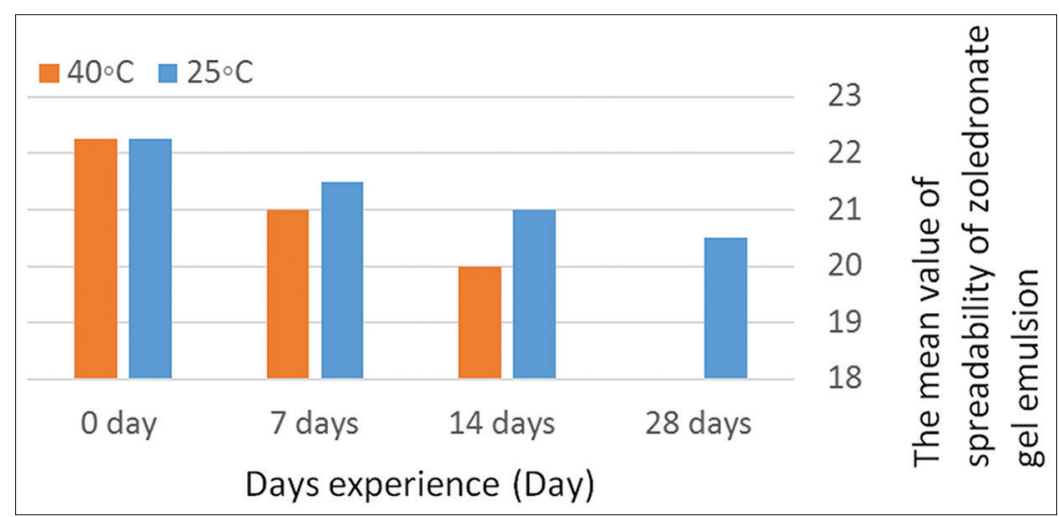

Fig. 3: Mean value of the spreadability of zoledronate (ZOL) gel emulsion at $25^{\circ} \mathrm{C}$ and $40^{\circ} \mathrm{C}$. Spreadability tests for the ZOL gel emulsion stored at $40^{\circ} \mathrm{C}$ over the 28 -day study period could not be performed due to the poor consistency of the gel emulsion 


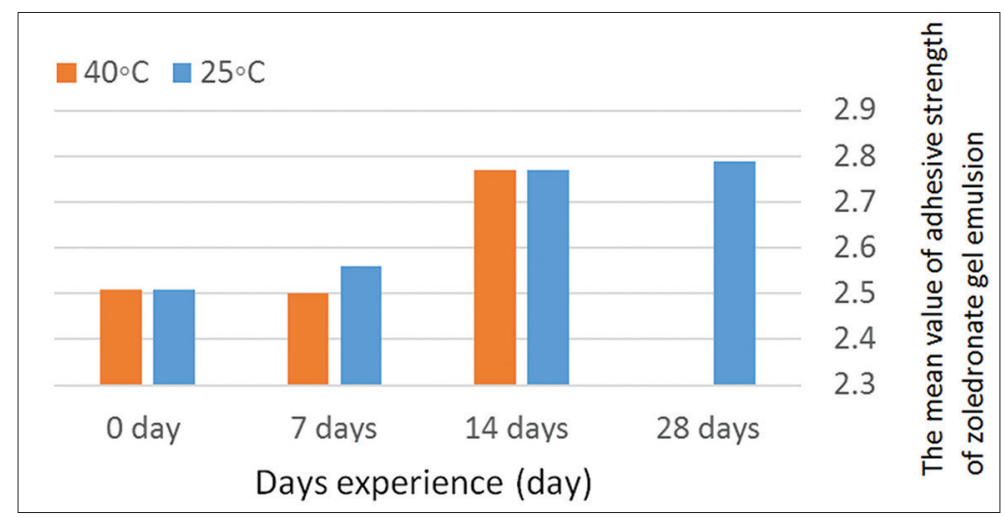

Fig. 4: Mean value of adhesive strength of zoledronate (ZOL) gel emulsion at $25^{\circ} \mathrm{C}$ and $40^{\circ} \mathrm{C}$. Adhesive strength tests for the $\mathrm{ZOL}$ gel emulsion stored at $40^{\circ} \mathrm{C}$ over the 28-day study period could not be performed due to the poor consistency of the gel emulsion

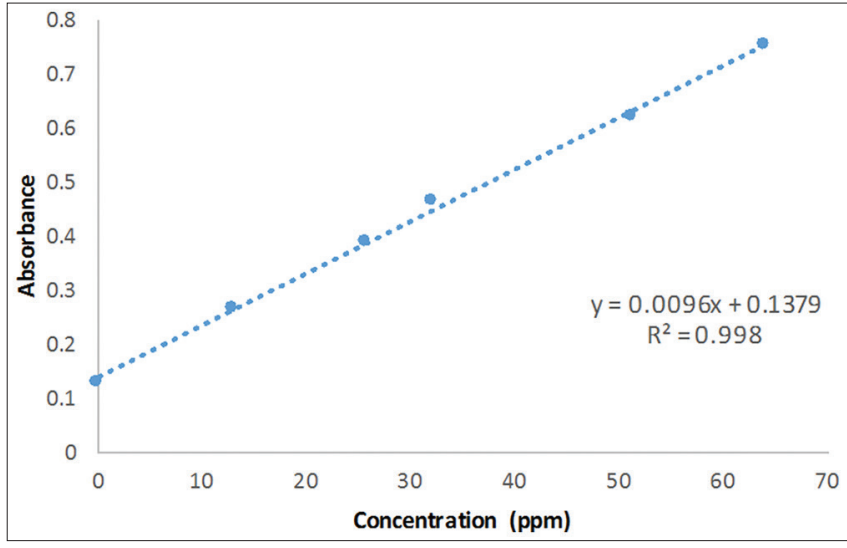

Fig. 5: Graph of the standard calibration curve of zoledronate bisphosphonates

significantly different from the value of the $1^{\text {st }}$ day of testing $(\mathrm{p}<0.05)$. Fig. 6 illustrates this degradation of drug content over the study period.

\section{DISCUSSION}

ZOL gel emulsions or emulgels are compounds that when mixed with VCO can become semi-solid after mixing with the gelling agent CMC. As a topical medication, gel emulsions have numerous advantages, such as the ability to deliver hydrophobic drugs that cannot be used in the form of a gel. Gel emulsions are also easily rubbed on the skin or mucous membranes due to their excellent ability to penetrate the skin [16-18]. VCO was selected as the oil base in this formulation because it has natural beneficial effects on health [19]. VCO is also characteristically smooth due to its fatty acid component, which serves as a penetration enhancer. Some studies have shown that VCO also has polyphenol and $\alpha$-tocopherols components that produce antioxidant effects and reduces cholesterols $[13,14]$. In our study, a preservative agent was added to the ZOL gel emulsion to prevent microbial growth and to maintain the oxygen in the oil base [20].

The $25^{\circ} \mathrm{C}$ temperature that chosen in this study represented the room temperature for drug storage and the $40^{\circ} \mathrm{C}$ reflected the accelerated testing for stability drugs in 28 days so the temperature must be raised [15]. The physical appearance of ZOL gel emulsion during the storage at $25^{\circ} \mathrm{C}$ showed that the formulation was stable and homogenous till day 28. The consistency and color of the gel emulsion were smooth and did not exhibit phase separation before or after the addition of the gelling agent, showing that the gel emulsion was stable [21]. Its color, taste, and odor were also acceptable. However, the consistency of the gel emulsion became solid at the $40^{\circ} \mathrm{C}$ storage by day 28; thus, all the evaluation tests could not be performed for samples stored at $40^{\circ} \mathrm{C}$.

In this study, the $\mathrm{pH}$ of the gel emulsion steadily decreased each week, dropping from 5.79 to 5.67. Some studies have reported that the fluctuation of $\mathrm{pH}$ value could be an indication of microbial growth, changes in temperature, poor storage condition, chemical reactions, or decomposition of the constituent ingredients [22]. Lee et al. reported that there is a relationship among the values of moisture content, $\mathrm{pH}$, and viscosity [23]. Decreasing moisture in the gel emulsion was similar to the effect of a decrease in its $\mathrm{pH}$ value [23]. In our study, the storage temperature was the leading cause for the reduction in the $\mathrm{pH}$ of the gel emulsion stored at $40^{\circ} \mathrm{C}$. The $\mathrm{pH}$ value of the gel emulsion after storing for 28 days at both temperatures was almost constant and stable. The $\mathrm{pH}$ value is similar to that of the oral cavity, which is approximately 6-7, which helps prevent irritation of the oral mucous [24].

The increment of the viscosity had a linear relationship with temperature $[24,25]$. Perhaps this anomalous viscosity-temperature behavior for gel emulsion could be caused by combinations of CMC, packaging, and temperature [26]. In-gel emulsions, CMC is the gelling agent. During storage, CMC as a gelling agent could be compromised and lead to a change in the resulting product. This phenomenon could be induced by temperature and packaging that is not airtight [24]. These factors could result in moisture absorption and increased water volume in the gel emulsion. Owen et al. reported that an increase in storage temperature also increases the apparent viscosity [25]. In addition, Iradhati and Juhfri noted that globule flocculation could increase the viscosity during the preparation of ZOL gel emulsion [21]. The fluctuation in the viscosity values on day 14 at $40^{\circ} \mathrm{C}$ storage and day 14 at $25^{\circ} \mathrm{C}$ storage might be caused by syneresis, the discharge of the entangled fluid in the gel emulsion to the surface [27].

The spreadability test was performed to determine the ability of the gel emulsion to spread on the skin and rapidly deliver its effectiveness [28]. The spreadability was reduce in the range of $2.2-2 \mathrm{~cm}$, confirming that it can spread uniformly and smoothly. This gel emulsion formulation also showed an inverse relationship between spreadability and viscosity. The gel emulsion with the highest viscosity also had the minimum spreadability on the skin or oral mucous and vice versa $[27,28]$. Some studies have concluded that the best spreadability value for oral mucous is in the range of $3-5 \mathrm{~cm}[28]$.

The adhesive strength value of ZOL gel emulsion ranged from 2.5 to $2.9 \mathrm{~s}$. The purpose of this test is to determine the duration of attachment of the gel to the skin [28]. This duration was found to be proportional to the viscosity of ZOL gel emulsion [27]. The values of spreadability and adhesive strength of the ZOL gel emulsion were below the average values for oral mucous, which contains saliva that can remove the gel emulsion quickly; hence, if the spreadability value is small and the 


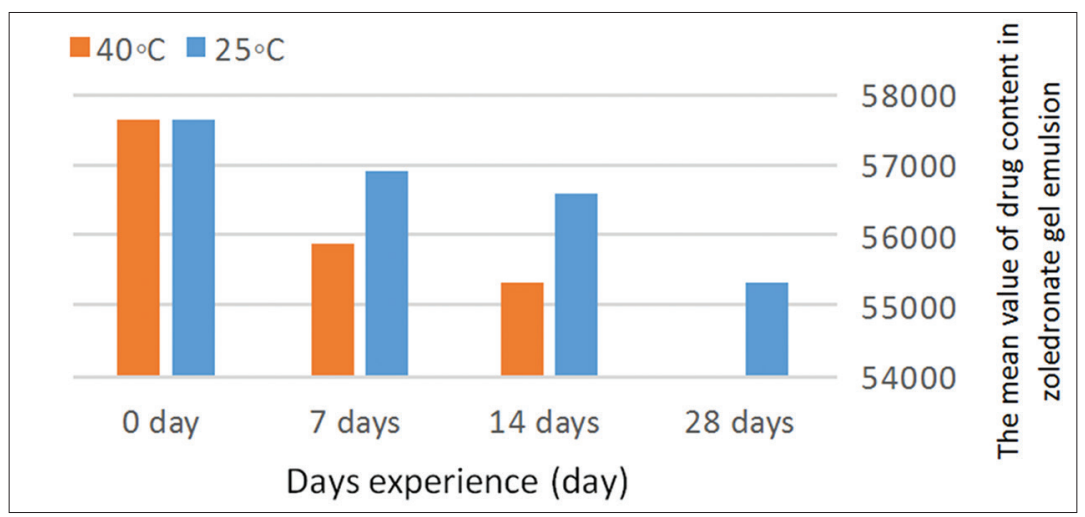

Fig. 6: Mean value of drug content in zoledronate (ZOL) gel emulsion at $25^{\circ} \mathrm{C}$ and $40^{\circ} \mathrm{C}$. Drug content tests for the ZOL gel emulsion stored at $40^{\circ} \mathrm{C}$ over the 28 -day study period could not be performed due to the poor consistency of the gel emulsion

duration of adhesive strength of ZOL gel emulsion is short, it will be favorable for effective drug delivery.

We found that degradation of the drug content in the ZOL gel emulsion was occurring, but not enough to jeopardize effective delivery of a therapeutic dose. The half-life of ZOL BP in bone is very long, ranging from 1 to 10 years and the degradation of this drug is still in the range of the half-life of ZOL [29,30].

Orthodontic tooth movement is characterized by the remodeling of periodontal and dental tissues by subjecting them to the mechanical force. The tooth movement produced by bone resorption on the compression side of the tooth that is induced by osteoclast and bone formation on the tension side that is induced by osteoblast $[8,31]$. Tooth movement in orthodontic treatment is not only aimed at shifting teeth appropriately but also simultaneously anchoring the tooth in its new position. However, undesired movement of the anchored teeth and relapse of moved teeth after orthodontic treatment are major clinical challenges for an orthodontist, both during and after orthodontic treatment [8]. According to Parlina et al., ZOL gel emulsion has the potential of inhibiting osteoclast activity and reducing bone resorption; thus, it may be effective in reducing the loss of anchorage and preventing relapse in orthodontic treatment [13]. From our study, it appears that the physical stability and drug content of the ZOL gel emulsion are sufficiently stable for its use by orthodontists.

\section{CONCLUSION}

This study found that the ZOL gel emulsion was stable when stored at $25^{\circ} \mathrm{C}$. The organoleptic, $\mathrm{pH}$, viscosity, spreadability, and adhesive strength values were also stable, and the degradation was constant. It is recommended that the storage of ZOL gel emulsion be at room temperature and in airtight containers. This study represented that ZOL gel emulsion was stable for clinical use, but the further in vitro study must be carried out.

\section{ACKNOWLEDGMENT}

The authors would like to thank Universitas Indonesia PITTA Grant (International Indexed Publication for UI Student's Final) 2018 committee for providing financial support for our research. In addition, we would like to thank Laboratory of Pharmaceutical Formulation and Development Universitas Indonesia and RCBE for providing the testing machines and facilities.

\section{CONFLICTS OF INTEREST}

There are no conflicts of interest to declare reported by the authors.

\section{REFERENCES}

1. Ortega AJ, Campbell PM, Hinton R, Naidu A, Buschang PH. Local application of zoledronate for maximum anchorage during space closure. Am J Orthod Dentofacial Orthop 2012;142:780-91.

2. Al-Awadhi EA, Garvey TM, Alhag M, Claffey NM, O'Connell B. Efficacy of the nance appliance as an anchorage-reinforcement method. Am J Orthod Dentofacial Orthop 2015;147:330-8.

3. Papageorgiou SN, Kutschera E, Memmert S, Gölz L, Jäger A, Bourauel C, et al. Effectiveness of early orthopaedic treatment with headgear: A systematic review and meta-analysis. Eur J Orthod 2017; 39:176-87

4. Bos A, Kleverlaan CJ, Hoogstraten J, Prahl-Andersen B, Kuitert R. Comparing subjective and objective measures of headgear compliance. Am J Orthod Dentofacial Orthop 2007;132:801-5.

5. Reynders R, Ronchi L, Bipat S. Mini-implants in orthodontics: Asystematicreview oftheliterature.AmJOrthodDentofacialOrthop2009; 135:564.e1-19.

6. Antoszewska-Smith J, Sarul M, Łyczek J, Konopka T, Kawala B. Effectiveness of orthodontic miniscrew implants in anchorage reinforcement during en-masse retraction: A systematic review and meta-analysis. Am J Orthod Dentofacial Orthop 2017;151:440-55.

7. Zahrowski JJ. Bisphosphonate treatment: An orthodontic concern calling for a proactive approach. Am J Orthod Dentofacial Orthop 2007; 131:311-20.

8. Krishnan V, Davidovitch Z. Cellular, molecular, and tissue-level reactions to orthodontic force. Am J Orthod Dentofacial Orthop 2006; 129:469.e1-32.

9. Graham JW. Bisphosphonates and orthodontics: Clinical implications. J Clin Orthod 2006; 7:425-8.

10. Adachi H, Igarashi K, Mitani H, Shinoda H. Effects of topical administration of a bisphosphonate (risedronate) on orthodontic tooth movements in rats. J Dent Res 1994;73:1478-86.

11. Kim TW, Yoshida Y, Yokoya K, Sasaki T. An ultrastructural study of the effects of bisphosphonate administration on osteoclastic bone resorption during relapse of experimentally moved rat molars. Am J Orthod Dentofacial Orthop 1999;115:645-53.

12. Liu L, Igarashi K, Haruyama N, Saeki S, Shinoda H, Mitani H, et al. Effects of local administration of clodronate on orthodontic tooth movement and root resorption in rats. Eur J Orthod 2004;26:469-73.

13. Parlina C, Purwaningsih E, Jusuf A, Widayati R. Impact of zoledronate bisphosphonates gel in virgin coconut oil on the increase of apoptosis osteoclast. Int J Appl Pharm 2017;9:24-7.

14. Sanjeewani NA, Sakeena MH. Formulation and characterization of virgin coconut oil (VCO) based emulsion. Int J Sci Res Publ 2013;3:2-7.

15. Bajaj S, Singla D, Sakhuja N. Stability testing of pharmaceutical products. J Appl Pharm Sci 2012;2:129-38.

16. Meenakshi D. Emulgel: A novel approach to topical drug delivery. Int J Pharm Biol Sci 2013;4:847-56.

17. Vats S, Saxena C, Easwari TS, Shukla VK. Emulsion based gel technique: Novel approach for enhancing topical drug delivery of hydrophobic drugs. Int J Pharm Res Sch. 2014;3:649-59.

18. Ajazuddin, Alexander A, Khichariya A, Gupta S, Patel RJ, Giri TK, et al. Recent expansions in an emergent novel drug delivery technology: Emulgel. J Control Release 2013;171:122-32.

19. Hayatullina Z, Muhammad N, Mohamed N, Soelaiman IN. Virgin coconut oil supplementation prevents bone loss in osteoporosis rat model. Evid Based Complement Alternat Med 2012;2012:237236.

20. Rowe R, Sheskey P, Quinn M. Handbook of Pharmaceutical Excipients. $6^{\text {th }}$ ed. London: RPS Publishing; 2009. 
21. Iradhati AH, Jufri M. Formulation and physical stability test of griseofulvin micremulsion gel. Int J Appl Pharm 2017;1:7-10.

22. Aslani A, Zolfaghari B, Davoodvandi F. Design, formulation and evaluation of an oral gel from Punica granatum flower extract for the treatment of recurrent aphthous stomatitis. Adv Pharm Bull 2016;6:391-8.

23. Lee SK, Anema S, Klostermeyer H. The influence of moisture content on the rheological properties of processed cheese spreads. Int J Food Sci Technol 2016;39:763-71.

24. Sayuti NA. Formulation and physical Sstability of Cassia alata L. leaf extract gel. J Kefarmasian Indones 2015;5:74-82.

25. Owen DH, Peters JJ, Lavine ML, Katz DF. Effect of temperature and pH on contraceptive gel viscosity. Contraception 2003;67:57-64.

26. Park NA, Irvine TF Jr. Anomalous viscosity-temperature behavior of aqueous carbopol solutions. $J$ Rheol 2003;41:167-73.

27. Wijayanto BA, Kurniawan DW, Sobri I. Formulation and effectiveness of antiseptic hand gel preparations containing galanga essential oils
(Alpinia galanga (L) Willd.)). J Ilmu Kefarmasian Indones. 2013; 11:102-7.

28. Riski R, Umar AH, Rismadani DP. Emulgel antiinflamation from extract of temulawak (Curcuma xanthorrhiza Roxb). J Pharm Med Sci 2016; $1: 1-4$

29. Sirisoontorn I, Hotokezaka H, Hashimoto M, Gonzales C, Luppanapornlarp S, Darendeliler MA, et al. Orthodontic tooth movement and root resorption in ovariectomized rats treated by systemic administration of zoledronic acid. Am J Orthod Dentofacial Orthop 2012;141:563-73.

30. Lin J. Bisphosphonates: A review of their pharmacokinetic properties. Bone 1996;18:75-85.

31. Keles A, Grunes B, Difuria C, Gagari E, Srinivasan V, Darendeliler MA, et al. Inhibition of tooth movement by osteoprotegerin vs. Pamidronate under conditions of constant orthodontic force. Eur J Oral Sci 2007; 115:131-6 